ISSN (e)-2347-176x ISSN (p) 2455-0450

crossref DOI: https://dx.doi.org/10.18535/jmscr/v5i11.11

Journal Of Medical Science And Clinical Research

\title{
A Study on Intraoperative and Post Operative Complications of Caeserian Section Related to Anesthesia in Rural Tertiary Centre
}

\author{
Authors \\ Dr Sujay ${ }^{1}$, Dr Santhosh Kumar ${ }^{2}$ \\ ${ }^{1}$ Assistant Professor in Anesthesia and Critical Care Kamineni Institute of Medical Sciences \\ ${ }^{2}$ Junior Pesident in Anesthesia and Critical Care Kamineni Institute of Medical Sciences \\ Email:drsujaym@gmail.com, santhoshkumar.n83@gmail.com \\ Corresponding Author \\ Dr Sujay \\ Assistant Professor in Anesthesia and Critical Care Kamineni Institute of Medical Sciences \\ Email:drsujaym@gmail.com
}

\begin{abstract}
Background: Cesarean section is the most common done obstetric emergency and the outcome of surgery differs depending on various factors. Maternal and fetal outcome depends on the profile of the patient and anaesthesia given.

Objectives: To study the anesthetic complications in rural referral patients (unbooked cases) undergoing emergency cesarean delivery and to compare them with booked cases undergoing emergency cesarean deliveries in Kamineni Institute Of Medical Sciences.

Purpose: This study was undertaken to find out the difference in anesthetic complications between booked cases with proper antenatal follow up and unbooked cases referred from rural health centres.

Method: The study is a cross-sectional study conducted at Kamineni Institute Of Medical Sciences from October 2013 - September 2015 over a period of 2 years. 560 cases of rural referrals (unbooked cases) undergoing emergency cesarean delivery were the study group. The control group consisted of 420 booked cases undergoing emergency cesarean delivery. Various parameters of maternal morbidity, neonatal morbidity and mortality due to anaesthesia were compared in both the groups.

Results: Of the various factors analysed in relation to type of Cesarean delivery, statistically significant associations were found between anaesthetic complications in emergency cesarean and younger patients, multi - parity, irregular attendance at antenatal clinic, no prenatal care.

Conclusion: Cesarean delivery done in rural referrals on emergency basis is associated with significant intra operative, post operative morbidity and neonatal morbidity and mortality related to anaesthesia. Every effort should be directed to proper antenatal care and planned cesarean delivery, as determined during antenatal period. Importance of an effective health care package and timely referral from peripheral hospitals should be stressed so as to reduce the various anaesthetic problems associated with emergency cesarean delivery.

Keywords: Emergency cesarean delivery, booked and unbooked, maternal morbidity, neonatal morbidity and mortality due to anaesthesia.
\end{abstract}




\section{Introduction}

Cesarean delivery is one of the most commonly performed operations today ${ }^{1}$. Obstetric practice has witnessed an increasing frequency in cesarean deliveries, in India it has increased from $26.6 \%$ (2007-2008) to $40.7 \%$ (2010-2011) ${ }^{2}$.

According to estimates of WHO 2015, world health statistics, the maternal mortality ratio is 560 (1990), 370 (2000), 190(2013) per 100,000 live births. $^{4}$

Inspite of all attempts to deliver the fetus by elective cesarean section, many times emergency cesarean section may have to be resorted for fetal or maternal salvage. The incidence of severe maternal morbidity due to Anaesthesia is significantly higher among women undergoing emergency cesarean section than women undergoing elective one. In emergency cases, there is lack of all the facilities, availability of trained staff, all the criteria may not be fulfilled, and both maternal and fetal complications are more common. Late referrals in case of obstructed labor, abnormal presentations, toxemia and inadequate transport facilities to apex hospital-this leads to increased risk of maternal and perinatal complications .

Present study was undertaken at Kamineni Institute Of Medical Sciences, which is a rural based medical college institute which is a tertiary referral center which has a patient population mainly from low socio economic status and rural areas. Patients were referred from private hospitals, cases handled by untrained dais and untrained medical personal then being referred to us as unbooked cases in an emergency state for management. These high risk rural referral cases (unbooked) are managed by anesthetists for emergency cesarean delivery which are compared to booked emergency cesarean deliveries, therefore it is essential to compare the outcome of cesarean deliveries in both situations due to anaesthesia, hence the need for study.
Aim

- To study the anaesthetic effects on maternal and fetal outcome of emergency caesarean delivery between unbooked rural referrals and booked cases at Kamineni Institute of Medical Sciences

\section{Objectives}

- To study the anaesthetic effects on maternal and fetal outcome of unbooked rural referrals who undergo emergency caesarean delivery at Kamineni Institute Of Medical Sciences

- To study the obstetric outcome of booked cases of Kamineni Institute Of Medical Sciences who undergo emergency caesarean delivery.

- To compare the obstetric outcome of unbooked rural referrals and booked cases of Kamineni Institute Of Medical Sciences who undergo anaesthesia emergency caesarean delivery at Kamineni Institute Of Medical Sciences .

- To study, evaluate and compare the risks and complications due to anaesthesia associated with emergency caesarean delivery in both booked and unbooked cases.

- To study and compare the demographic characters of both groups.

\section{Patients and Methods}

Place of Study: This study was conducted in the Department of Anaesthesia at Kamineni institute of medical sciences, Narketpally.

Period of Study: October 2013 to September 2015.

Type of Study: Comparative cross sectional study Study population:

- Study group: 560 cases of rural referrals (unbooked cases) undergoing anaesthesia for emergency cesarean delivery.

- Control group: 420 booked cases undergoing Anaesthesia emergency cesarean delivery. 
The necessary permission and approval from the Hospital ethics committee was taken.

Written informed consent was obtained from the patients.

\section{Inclusion Criteria}

- Gestational age > 37 weeks

- Unbooked cases handled outside and referred, who underwent Anesthesia cesarean delivery on emergency.

- Booked cases admitted in our hospital and underwent anesthesia emergency cesarean delivery.

- Single ton pregnancy.

\section{Exclusion Criteria}

- Gestational age < 37 weeks

- Multiple gestations

- Booked and unbooked cases admitted in our hospital for elective cesarean delivery under anesthesia.

\section{Method of Collection of Data}

Kamineni institute of medical sciences is a rural based medical college in Narketpally, Telangana situated $100 \mathrm{kms}$ from Hyderabad, surrounded by about 130 villages. Kamineni institute of medical sciences is a tertiary care centre having a large number of referral cases (unbooked patients) from these areas. Hospital is well equipped and has round the clock availability of qualified team comprising of obstetricians, pediatricians and anesthesiologists and blood bank facility.

The main source of data for this study were 560 patients (unbooked) who were handled in PHC's, CHC's, private nursing homes, untrained dais and referred to us considered as unbooked cases, who underwent emergency cesarean delivery and 420 patients who were booked and posted for emergency cesarean delivery during the study period.

Booked mothers were those who had attended minimum of three antenatal clinics in our institute, first visit at 20 weeks or as soon as pregnancy is known, second visit at 32 weeks and third visit at 36 weeks.
Unbooked mothers were those who had no prenatal care during their whole pregnancy and those who were referred in emergencies from other medical centers and hospitals. ${ }^{89}$

Demographic variables included age, socioeconomic status and education status. Obstetric history included parity status, maternal health before and during pregnancy, significant clinical events in previous pregnancy and detailed information regarding complication occurring intrapartum and postpartum. Medical evaluations including medical disorders like diabetes mellitus, hypertension, cardiac disease thyroid disorders which can show their impact on maternal and fetal outcome was obtained.

In booked group on admission detailed history was taken, routine investigations were done. Pre Anesthetic check up was done prior to surgery. The procedure was explained and informed written consent was obtained. Patient was advised NPO and pre medicated with tab. Ranitidine and pre loaded with IV Infusion of 1 Ltr of Ringer Lactate solution $1 \mathrm{hr}$ before the procedure.

In unbooked cases on admission to hospital with a referral letter from the peripheral centre, detailed history such as Name, age, parity, socio economic status, whether, handled at home or untrained dais, at PHC's by health workers, medical officer's or at private nursing home were noted.

Reason for referral, distance travelled, mode of transport to reach our institution, reasons for not attending antenatal clinic were also noted.

A complete obstetric history was taken, duration of pregnancy, duration of onset of pain, H/O vaginal leak or bleeding. Method of intervention like use of oxytocin, epidosin, ARM was noted.

Detailed past obstetric history, menstrual history, family and personal history, medical and surgical history were noted. All these were recorded on predesigned proforma.

Fetal well being was assessed with ultrasonography and cardiotocography.

Maternal outcome measures were followed for mortality and morbidity, which can be due to major obstetric or postpartum haemorrhage, 
puerperal sepsis, wound infection DIC,ARF, pulmonary edema, and postoperative mechanical ventilation. Postpartum haemorrhage is defined as a blood loss of more than $500 \mathrm{ml}$ in the first 24 hours following delivery of the fetus in vaginal deliveries and more than $1000 \mathrm{ml}$ in cesarean deliveries. Severe or massive PPH is defined as a blood loss of more than $150 \mathrm{ml}$ per minute or a sudden loss of more than 1500 to $2000 \mathrm{ml}$.

The ACOG has defined PPH as a hematocrit drop of 10 percent or more, or a haemorrhage that requires immediate blood transfusion. ${ }^{90}$

All complications that occurred during labour, intra-operative period, post-operative period, postnatal hospital stay were recorded.

Severe maternal morbidity is described as Maternal Near Miss (MNM). Maternal Near Miss case is defined as "a woman who nearly died but survived a complication that occurred during pregnancy, childbirth, or within 42 days of termination of pregnancy".

Fetal outcome studied were perinatal mortality (stillborn or neonatal death). Stillbirth or fetal death is defined as" the absence of signs of life at or after birth". Early neonatal death is defined as "death of a live born neonate during the first seven days after birth". Late neonatal death is defined as "death after 7 days but before 29 days ".

New born weight was recorded, APGAR scoring done, after pediatric examination those with birth asphyxia were admitted to Neonatal Intensive Care Unit (NICU) and each new born was followed till discharge from the hospital.

Collected data entered in the proforma were analysed, significance of difference of various morbidities in the two groups were calculated by pearsons chi-square test.

$P$ value $<0.05$ is taken as significant.
Table 1- Comparison of Incidence of emergency cesarean section in booked vs un-booked group with other studies

\begin{tabular}{|c|c|c|c|}
\hline S.no & Study group & Booked & Un-booked \\
\hline 1 & $\begin{array}{l}\text { Vidyadhar et al } \\
(2012)^{84}\end{array}$ & $\begin{array}{c}\mathrm{n}=389 \\
27 \%\end{array}$ & $\begin{array}{c}\mathrm{n}=476 \\
73 \%\end{array}$ \\
\hline 2 & $\begin{array}{l}\text { Gulfareen et al } \\
(2009)^{93}\end{array}$ & $\begin{array}{l}n=167 \\
43.9 \%\end{array}$ & $\begin{array}{c}\mathrm{n}=213 \\
56 \%\end{array}$ \\
\hline 3 & $\begin{array}{c}\text { Vijayasree M } \\
(2015)^{92}\end{array}$ & $\begin{array}{l}n=238 \\
47.6 \%\end{array}$ & $\begin{array}{l}\mathrm{n}=262 \\
52.4 \%\end{array}$ \\
\hline 4 & $\begin{array}{c}\text { Nargis D et al } \\
(2010)^{94}\end{array}$ & $\begin{array}{l}\mathrm{n}=52 \\
23.5 \%\end{array}$ & $\begin{array}{c}\mathrm{n}=270 \\
76.5 \%\end{array}$ \\
\hline 5 & $\begin{array}{c}\text { Iklaki et al } \\
(2012)^{95}\end{array}$ & $\begin{array}{c}\mathrm{n}=245 \\
19 \%\end{array}$ & $\begin{array}{c}n=399 \\
50 \%\end{array}$ \\
\hline 6 & $\begin{array}{c}\text { Present study } \\
\text { (oct 2013- sep 2015) }\end{array}$ & $\begin{array}{c}n=420 \\
42.86 \%\end{array}$ & $\begin{array}{c}\mathrm{n}=560 \\
57.14 \%\end{array}$ \\
\hline
\end{tabular}

In the present study the incidence of emergency cesarean section was more in the unbooked group and is comparable with the other studies as shown in the above table.

In a study of referred cases from rural areas done by Limaye et al, cesarean delivery was 6 times higher in referred unbooked cases.

Kim et al.(2012) has proposed that timely referral within and to Emergency Obstetric Newborn Care (EmONC) facilities would decrease the proportion of CS deliveries that develop to emergency status. He also proposed that it could have been because of negligence of understanding the seriousness of patients condition, financial constraints, referral system and non availability of transport to shift patients towards tertiary care centres which makes condition among unbooked group further complicated resulting in emergency caesarean section. 
Table- 2 Comparison of distribution of Age of the study subjects with other studies

\begin{tabular}{|c|c|c|c|c|c|c|c|c|c|c|}
\hline \multirow{3}{*}{$\begin{array}{l}\text { Age } \\
\text { group } \\
\text { (in } \\
\text { Yrs) }\end{array}$} & \multicolumn{10}{|c|}{ Study groups } \\
\hline & \multicolumn{2}{|c|}{ Jaspinder et al $^{88}$ (2013) } & \multicolumn{2}{|c|}{$\begin{array}{l}\text { Riffat J et al } \\
\quad(2008)^{97}\end{array}$} & \multicolumn{2}{|c|}{$\begin{array}{l}\text { Mundhra R et al } \\
\quad(2013)^{98}\end{array}$} & \multicolumn{2}{|c|}{$\begin{array}{l}\text { Rajal Thaker et al } \\
\qquad(2013)^{99}\end{array}$} & \multicolumn{2}{|c|}{ Present study } \\
\hline & $\begin{array}{c}\mathrm{B} \\
\mathrm{n}=42\end{array}$ & $\begin{array}{c}\mathrm{UB} \\
\mathrm{n}=58\end{array}$ & $\begin{array}{c}\mathrm{B} \\
\mathrm{n}=388\end{array}$ & $\begin{array}{c}\mathrm{UB} \\
\mathrm{n}=347\end{array}$ & $\begin{array}{c}\mathrm{B} \\
\mathrm{n}=323\end{array}$ & $\underset{n=479}{\mathrm{UB}}$ & $\begin{array}{c}\mathrm{B} \\
\mathrm{n}=952\end{array}$ & $\begin{array}{c}\mathrm{UB} \\
\mathrm{n}=219\end{array}$ & $\begin{array}{c}\mathrm{B} \\
\mathrm{n}=420\end{array}$ & $\begin{array}{c}\mathrm{UB} \\
\mathrm{n}=560\end{array}$ \\
\hline$<20 \mathrm{yrs}$ & $1(2.39 \%)$ & $\begin{array}{c}9 \\
(15.52 \%)\end{array}$ & $\begin{array}{c}15 \\
(3.9 \%)\end{array}$ & $\begin{array}{c}20 \\
(5.8 \%)\end{array}$ & $\begin{array}{c}20 \\
(6.19 \%)\end{array}$ & $\begin{array}{c}52 \\
(10.85 \%)\end{array}$ & $\begin{array}{c}73 \\
(7.6 \%)\end{array}$ & $\begin{array}{c}18 \\
(0.2 \%)\end{array}$ & $\begin{array}{c}26 \\
(6.19 \%)\end{array}$ & $\begin{array}{c}61 \\
(10.85 \%)\end{array}$ \\
\hline $\begin{array}{l}20-30 \\
\text { yrs }\end{array}$ & $\begin{array}{c}30 \\
(71.44 \%)\end{array}$ & $\begin{array}{c}45 \\
(77.60 \%)\end{array}$ & $\begin{array}{c}367 \\
(94.6 \%)\end{array}$ & $\begin{array}{c}309 \\
(89 \%)\end{array}$ & $\begin{array}{c}292 \\
(90.4 \%)\end{array}$ & $\begin{array}{c}368 \\
(76.83 \%)\end{array}$ & $\begin{array}{c}763 \\
(80.1 \%)\end{array}$ & $\begin{array}{c}159 \\
(72.5 \%)\end{array}$ & $\begin{array}{c}380 \\
(90.4 \%)\end{array}$ & $\begin{array}{c}430 \\
(76.83 \%)\end{array}$ \\
\hline$>30 \mathrm{yrs}$ & $\begin{array}{c}11 \\
(26.20 \%)\end{array}$ & $\begin{array}{c}4 \\
(6.9 \%)\end{array}$ & $\begin{array}{c}6 \\
(1.5 \%)\end{array}$ & $\begin{array}{c}18 \\
(5.2 \%)\end{array}$ & $\begin{array}{c}11 \\
(3.41 \%)\end{array}$ & $\begin{array}{c}59 \\
(12.32 \%)\end{array}$ & $\begin{array}{c}116 \\
(12 \%)\end{array}$ & $\begin{array}{c}42 \\
(19.1 \%)\end{array}$ & $\begin{array}{c}14 \\
(3.41 \%)\end{array}$ & $\begin{array}{c}69 \\
(12.32 \%)\end{array}$ \\
\hline
\end{tabular}

As shown in the above table, the maximum number of cases were seen between 20-30 yrs of age group in both booked and unbooked group. Teenage pregnancy was more in unbooked group i.e $10.85 \%$ compared to booked group which is only $6.19 \%$, in the present study, which is comparable and similar in other studies.
Jaspinder et al (2013) stated that young age along with lack of awareness regarding importance of antenatal care and lack of education especially health education might have withdrawn them from taking antenatal care at an early gestational age or till the development of obstetric complications. This led to their higher number in unbooked group

Table 3 Comparison of distribution of study subjects in relation to parity with other studies

\begin{tabular}{|l|c|c|c|c|c|c|}
\hline \multirow{3}{*}{ Parity } & \multicolumn{9}{|c|}{\begin{tabular}{c} 
Study groups \\
\cline { 2 - 7 }
\end{tabular}} & \multicolumn{2}{|c|}{$\begin{array}{c}\text { Jaspinder et al } 88 \\
(2013)\end{array}$} & \multicolumn{2}{c|}{$\begin{array}{c}\text { Rajal Thaker et al } \\
(2013) 99\end{array}$} & \multicolumn{2}{c|}{ Present study } \\
\cline { 2 - 7 } & $\begin{array}{c}\mathrm{B} \\
\mathrm{n}=42\end{array}$ & $\begin{array}{c}\mathrm{UB} \\
\mathrm{n}=58\end{array}$ & $\begin{array}{c}\mathrm{B} \\
\mathrm{n}=952\end{array}$ & $\begin{array}{c}\mathrm{UB} \\
\mathrm{n}=219\end{array}$ & $\begin{array}{c}\mathrm{B} \\
\mathrm{n}=420\end{array}$ & $\begin{array}{c}\mathrm{UB} \\
\mathrm{n}=560\end{array}$ \\
\hline Primi & 19 & 36 & 402 & 100 & 168 & 194 \\
$(45.24 \%)$ & $(62.07 \%)$ & $(42.2 \%)$ & $(45.6 \%)$ & $(39.9 \%)$ & $(34.6 \%)$ \\
\hline Multi & $\begin{array}{c}23 \\
(54.77 \%)\end{array}$ & $\begin{array}{c}22 \\
(37.94 \%)\end{array}$ & $\begin{array}{c}550 \\
(57.6 \%)\end{array}$ & $\begin{array}{c}119 \\
(54.1 \%)\end{array}$ & $\begin{array}{c}252 \\
(60.1 \%)\end{array}$ & $\begin{array}{c}366 \\
(65.4 \%)\end{array}$ \\
\hline
\end{tabular}

As shown in the above table, there is higher percentage of multiparity in unbooked group i.e $65.4 \%$ compared to booked group, which was similar to other studies. In a study conducted by Mundhra R etal (2013), a significantly higher percentage of multiparous patients $(24.84 \%)$ were unbooked and she stated that this was most likely because these mothers had previous successful deliveries without antenatal care and therefore they felt assured and did not feel the need to seek antenatal care in the present pregnancy and she also proposed that this could be attributed to their lower educational and lower socio-economic status, as a result of which they were not aware of the need for birth spacing and the importance of contraceptive measures. 
Table -4 Comparison of Socioeconomic status of study subjects with other studies

\begin{tabular}{|c|c|c|c|c|c|c|c|c|}
\hline \multirow{3}{*}{$\begin{array}{l}\text { Economic } \\
\text { status }\end{array}$} & \multicolumn{8}{|c|}{$\begin{array}{l}\text { Study groups } \\
\end{array}$} \\
\hline & \multicolumn{2}{|c|}{$\begin{array}{c}\text { Mundhra R et al }^{98} \\
\text { (2013) }\end{array}$} & \multicolumn{2}{|c|}{$\begin{array}{c}\text { Jaspinder et al }^{88} \\
(2013)\end{array}$} & \multicolumn{2}{|c|}{$\begin{array}{c}\text { Vijayasree M } \\
(2015)^{92}\end{array}$} & \multicolumn{2}{|c|}{ Present study } \\
\hline & $\begin{array}{c}\mathrm{B} \\
\mathrm{n}=323\end{array}$ & $\begin{array}{c}\text { UB } \\
n=479\end{array}$ & $\underset{n=42}{B}$ & $\begin{array}{c}\mathrm{UB} \\
\mathrm{n}=58\end{array}$ & $\begin{array}{c}\mathrm{B} \\
\mathrm{n}=238 \\
\end{array}$ & $\begin{array}{c}\mathrm{UB} \\
\mathrm{n}=262\end{array}$ & $\begin{array}{c}B \\
n=420\end{array}$ & $\begin{array}{c}\text { UB } \\
\mathrm{n}=560\end{array}$ \\
\hline Upper & $\begin{array}{c}30 \\
(9.29 \%) \\
\end{array}$ & $\begin{array}{c}0 \\
(0 \%) \\
\end{array}$ & $\begin{array}{c}11 \\
(26.2 \%) \\
\end{array}$ & $\begin{array}{c}5 \\
(8.63 \%) \\
\end{array}$ & - & - & $\begin{array}{c}8 \\
(1.9 \%) \\
\end{array}$ & $\begin{array}{c}0 \\
(0 \%) \\
\end{array}$ \\
\hline $\begin{array}{l}\text { Upper } \\
\text { middle }\end{array}$ & $\begin{array}{c}101 \\
(31.27 \%)\end{array}$ & $\begin{array}{c}24 \\
(5.01 \%)\end{array}$ & & & - & - & $\begin{array}{c}51 \\
(12.07 \%)\end{array}$ & $\begin{array}{c}26 \\
(4.55 \%)\end{array}$ \\
\hline $\begin{array}{l}\text { Lower } \\
\text { middle }\end{array}$ & $\begin{array}{c}95 \\
(29.41 \%)\end{array}$ & $\begin{array}{c}96 \\
(20.04 \%)\end{array}$ & $\begin{array}{c}31 \\
(73.81 \%)\end{array}$ & $\begin{array}{c}36 \\
(62.07 \%)\end{array}$ & - & - & $\begin{array}{c}152 \\
(36.21 \%)\end{array}$ & $\begin{array}{c}127 \\
(22.73 \%) \\
\end{array}$ \\
\hline $\begin{array}{l}\text { Upper } \\
\text { lower }\end{array}$ & $\begin{array}{c}97 \\
(30.03 \%)\end{array}$ & $\begin{array}{c}359 \\
(74.95 \%)\end{array}$ & & & - & - & $\begin{array}{c}123 \\
(29.31 \%)\end{array}$ & $\begin{array}{c}175 \\
(31.22 \%)\end{array}$ \\
\hline Lower & $\begin{array}{c}0 \\
(0 \%)\end{array}$ & $\begin{array}{c}0 \\
(0 \%)\end{array}$ & $\begin{array}{c}0 \\
(0 \%)\end{array}$ & $\begin{array}{c}17 \\
(29.32 \%)\end{array}$ & $18.06 \%$ & $61.8 \%$ & $\begin{array}{c}86 \\
(20.51 \%)\end{array}$ & $\begin{array}{c}232 \\
(41.5 \%)\end{array}$ \\
\hline
\end{tabular}

Our study found the relation between unbooked category and lower socio-economic status $(\mathrm{p}<0.05$, $41.5 \%$ ) which has been consistent with other studies (Jaspinder etal 2013 ) as shown in the above table. Jaspinder etal (2013) described that mothers with low socio-economic scale either approach for antenatal care in late pregnancy or during delivery with complicated stage of labour.
On the other side mothers of high socio-economic scale had higher number in booked group as compared to their counterpart and he also revealed that financial issue which includes cost of antenatal services and transportation might be cited as one of the factors affecting utilization of antenatal care.

Table-5 Comparison of Education status of study subjects with other studies

\begin{tabular}{|c|c|c|c|c|c|c|}
\hline \multirow{3}{*}{$\begin{array}{l}\text { Educational } \\
\text { qualification }\end{array}$} & \multicolumn{6}{|l|}{ Study groups } \\
\hline & \multicolumn{2}{|c|}{$\begin{array}{l}\text { Rajal thaker et al } \\
(2013)^{99}\end{array}$} & \multicolumn{2}{|c|}{$\begin{array}{l}\text { Ursula M Botha } \\
(2004)^{100}\end{array}$} & \multicolumn{2}{|l|}{ Present study } \\
\hline & $\begin{array}{l}B \\
n=952\end{array}$ & $\begin{array}{l}\text { UB } \\
\mathrm{n}=219\end{array}$ & $\begin{array}{l}B \\
n=200\end{array}$ & $\begin{array}{l}\text { UB } \\
n=100\end{array}$ & $\begin{array}{l}B \\
n=420\end{array}$ & $\begin{array}{l}\text { UB } \\
\mathrm{n}=560\end{array}$ \\
\hline illiterate & $184(19.3 \%)$ & $76(34.7 \%)$ & \multirow{2}{*}{$\begin{array}{l}71 \\
(35.5 \%)\end{array}$} & \multirow{2}{*}{$\begin{array}{l}54 \\
(54 \%)\end{array}$} & $78(18.5 \%)$ & $218(39 \%)$ \\
\hline Primary edu. & $474(49.7 \%)$ & $92(42 \%)$ & & & $218(52 \%)$ & $233(41.5 \%)$ \\
\hline Secondary edu. & $263(27.6 \%)$ & $47(21.4 \%)$ & \multirow{2}{*}{$129(64.5 \%)$} & \multirow{2}{*}{$\begin{array}{l}46 \\
(46 \%)\end{array}$} & $120(28.5 \%)$ & $109(19.5 \%)$ \\
\hline Tertiary & $\begin{array}{l}31 \\
(3.2 \%)\end{array}$ & $\begin{array}{l}4 \\
(1.8 \%)\end{array}$ & & & $4(1 \%)$ & $0(0 \%)$ \\
\hline
\end{tabular}

As shown in the above table majority of unbooked group i.e $39 \%$ were illiterate compared to booked group which was $18.5 \%$.. This was consistent with other studies which was $34.7 \%$ in unbooked group in a study conducted by Rajal thaker etal (2013) where as it was $19.3 \%$ in booked group in his study. This shows that poor educational status is a contributing factor for improper utilization of antenatal care.

\section{Discussion}

More than 500,000 women die of childbirth every year worldwide at present. One woman dies and twenty other suffer from injury or disease because of childbirth every minute. Of these, India alone accounts for about 100,000 maternal deaths every year, with an overall maternal mortality rate of 407 per 100,000 live births. The rate varies from state to state, being highest in Utter Pradesh and Rajasthan (707 and 677 respectively) and lowest 
in Tamil Nadu and Gujarat (76 and 29 respectively).

The maternal health programme, a component of the Reproductive and Child Health Programme, aims at reducing maternal mortality to less than 180 by the year 2010 by the provision of essential and emergency obstetric care, facilitating referral transport, safe abortion and the detection and treatment of reproductive tract infections. (Ian Donald). Most maternal deaths are due to hemorrhage, anemia and puerperal complications, obstructed labour, PIH, anemia and infections and the vast majority would be preventable with universal access to antenatal care and an effective system or referral.

The question why some women do not attend antenatal clinics and how this affects the outcome of pregnancy is of clinical importance because of the persistently high proportion of unbooked patients delivered. The majority of the unbooked mothers take up little of the doctors' time because they receive minimal or no antenatal care and spend only a short time in hospital for delivery.

Late referrals in case of obstructed labor, abnormal presentations, toxemia and inadequate transport facilities to apex hospital-this leads to increased risk of maternal and perinatal complications $^{8}$. Improper antenatal and intranatal care at peripheral level is responsible for poor maternal and perinatal outcome ${ }^{9}$.

Unbooked mothers make a substantial contribution to perinatal morbidity and mortality. The initial aims before assessing the fetal outcome were to attempt to discover the basic reasons for their failure to attend antenatal clinics.

In this study 980 cases were enrolled in the study out of which $420(42.86 \%)$ were booked cases and $560(57.14 \%)$ were unbooked cases who underwent emergency Lscs and it was observed that maternal morbidity was lower in the booked group as compared to the unbooked group.

This study aimed to compare the sociodemographical characteristics, obstetrical complications and fetal and maternal outcomes in pregnant women booked for antenatal care and delivery in our centre were compared with that of women unbooked for antenatal care in our centre or brought in during the course of labour because of onset of complications, but without any records of her antenatal care being forwarded.

\section{Conclusion}

The following conclusions can be obtained from the present study.

- Booked antenatal patients have better maternal outcome when compared to Unbooked patients.

- Booked antenatal patients have better perinatal outcome when compared to Unbooked antenatal patient.

- Present study shows qualitatively similar pattern of results when compared to other studies.

- This study shows a strong association between unbooked status and risks of maternal and fetal adverse outcomes.

- The present study showed that poor utilization of antenatal care is associated with increased maternal and perinatal morbidity and mortality.

- Complications can arise at anytime during pregnancy, childbirth and postnatal period and in the absence of intervention, there is high feto-maternal morbidity and mortality.

- Ceasarean delivery in rural referrals on emergency basis is associated with significant intraoperative and postoperative morbidity and perinatal morbidity and mortality.

- This study emphasis that High Risk pregnancy identification and proper antenatal, intranatal and postnatal care will reduce the incidence of obstetric emergencies.

- Reduction in poverty, illiteracy and improvement in health awareness in women will help in making pregnancy safe. 
- Strengthening of primary and secondary level facilities and timely referral to tertiary care level plays a crucial role in decreasing maternal morbidity as well as various problems associated with emergency cesarean delivery.

- Multidisciplinary team approach can provide optimal care for the Near-Miss patients and thereby help in reducing maternal and perinatal morbidity and mortality.

- This study concluded that with proper antenatal, intranatal and postnatal care, maternal and neonatal morbidity and mortality can be reduced and MILLENIUM DEVELOPMENT GOALS can be achieved.

\section{References}

1. Mitchell CK, Smoger SH, Pfeifer MP, Vogel RL, Pandit MK, Donnelly PJ, Garrison RN, Rothschild MA: Multivariate analysis of factors associated with postoperative pulmonary complications following general elective surgery. Arch Surg 1998; 133:194-8Mitchell, CK Smoger, SH Pfeifer, MP Vogel, RL Pandit, MK Donnelly, PJ Garrison, RN Rothschild, MA

2. McAlister FA, Bertsch K, Man J, Bradley $\mathrm{J}$, Jacka M: Incidence of and risk factors for pulmonary complications after nonthoracic surgery. Am J Respir Crit Care Med 2005; 171:514-7McAlister, FA Bertsch, K Man, J Bradley, J Jacka, M

3. Maskell NA, Butland RJ, Pleural Diseases Group, Standards of Care Committee, British Thoracic Society: BTS guidelines for the investigation of a unilateral pleural effusion in adults. Thorax 2003; 58(suppl 2):ii8-17Maskell, NA Butland, RJ Pleural Diseases Group, Standards of Care Committee, British Thoracic Society,
4. Duggan M, Kavanagh BP: Pulmonary atelectasis: A pathogenic perioperative entity. Anesthesiology 2005; 102:838-54 Duggan, M Kavanagh, BP5 BrooksBrunn JA: Postoperative atelectasis and pneumonia. Heart Lung 1995; 24:94115Brooks-Brunn, JA 